\title{
REPRODUCTION AT ALL COSTS: THE ADAPTIVE STRESS RESPONSE OF MALE ARCTIC GROUND SQUIRRELS
}

\author{
Rudy Boonstra, ${ }^{1}$ Carolyn J. McColl, and Tim J. Karels \\ Division of Life Sciences, University of Toronto at Scarborough, 1265 Military Trail, \\ Scarborough, Ontario, Canada MIC 1A4
}

\begin{abstract}
We tested the hypothesis that adult male arctic ground squirrels (Spermophilus parryii plesius) exhibit an adaptive stress response during the mating period that may compromise their survival, whereas males at other times (nonreproductive adult males and juvenile males) have a normal functional stress response. We assessed the physiological responsiveness of the stress axis, of energy mobilization, and of the immune response by subjecting adult breeding males, adult nonbreeding males, and juvenile males to a hormonal challenge and an immunocompetence challenge. At the onset of the breeding season in spring, only $25-30 \%$ of the population were males, and of those present during the mating period, half disappeared soon thereafter, and $82 \%$ were not replaced by immigrants. Adult breeding males had the highest levels of free cortisol, the lowest maximum corticosteroidbinding capacity, slight dexamethasone resistance, the lowest hematocrit, the lowest number of white blood cells, the highest number of eosinophils, and the poorest ability to respond to the foreign antigen challenge in comparison with the other two male classes. All of these characteristics were indicative of chronic stress in breeding males that may directly compromise their survival. Juvenile males in mid-August also showed many, but not all of these characteristics, indicative of a prolonged period of stress, presumably associated with the period of dispersal. Testosterone levels remained high irrespective of age or breeding condition, decreased when dexamethasone was injected, and increased when ACTH was injected. These latter results are unique in mammals. High testosterone levels and their augmentation with stressors may play a key role in maintenance of aggressive behavior. We conclude that breeding male arctic ground squirrels exhibit an adaptive stress response in which they trade off survival for reproduction. We hypothesize that similar stress responses may have evolved in other species with comparable life histories.
\end{abstract}

Key words: adaptive stress; arctic ground squirrels; dexamethasone-ACTH challenge; energy mobilization; field endocrinology; hypothalamic-pituitary-adrenal axis; immunosuppression; life history; reproduction; Spermophilus parryii plesius; testosterone; Yukon.

\section{INTRODUCTION}

For male mammals that engage in direct, intense intrasexual competition, reproduction can be very stressful. Many stressors to which animals are exposed occur unpredictably (such as a predator attack) and evoke a rapid response that results in an immediate, short-term activation of the hypothalamic-pituitary-adrenal (HPA) axis for a "flight or fight" response (Selye 1946, Lee and McDonald 1985, Sapolsky 1992). However, stressors associated with reproduction may be long term and predictable, and may evoke an evolved response that differs from the short-term activation of the HPA. For example, in a variety of dasyurid marsupials (Antechinus spp. [Bradley et al. 1980, McDonald et al. 1981] and Phascogale calura [Bradley 1987]), the males live $\sim 11$ months, breed frantically, and die before their offspring are born. The proximate cause of death is a failure of their immune and inflammatory responses caused by a dysfunctional HPA axis.

Manuscript received 1 December 1999; revised 22 July 2000; accepted 31 July 2000; final version received 16 August 2000.

${ }^{1}$ E-mail: boonstra@scar.utoronto.ca
The ultimate cause of death may be that this failure of the axis is adaptive, in that it promotes reproductive fitness by allowing the males to redirect all of their energy to reproduction, minimizing the time needed to forage, but at the expense of postmating survival (Lee and Cockburn 1985).

Boonstra and Boag (1992) proposed that similar adaptive stress responses may occur in mammalian species that have life histories similar to those of the dasyurids (i.e., one intense breeding opportunity per year and low between-year survival). In many ground squirrel species, the breeding period may last no more than 2-3 weeks; during this period, males roam widely, sustain more injuries, eat less, and lose more mass than females. This intense mating period is followed by higher mortality rates immediately after breeding in males than in females (Morton and Sherman 1978, McLean and Towns 1981, Michener and Locklear 1990, Michener and McLean 1996). Our objective was to examine postmating survival in male arctic ground squirrels (Spermophilus parryii plesius) and to test the hypothesis that breeding males during the mating period exhibit a stress response that may compromise 
their survival, whereas males at other times (nonreproductive adult males and juvenile males in late summer) have a normal stress response.

The HPA axis is key in vertebrates in coordinating the stress response to challenges. It is pivotal in that it generally operates to maintain homeostasis, permitting rapid, short-term responses to acute challenges and then reestablishing baseline conditions through negative feedback to the brain (Sapolsky 1992). In response to acute stressors, the HPA axis initiates a cascade of hormonal changes that ultimately have catabolic consequences, causing a release of adrenal corticosteroids (cortisol in ground squirrels) that stimulates hepatic gluconeogenesis, inhibition of glucose uptake by peripheral tissues, mobilization of fat stores as an energy substrate for the liver, suppression of the inflammatory response, suppression of the immune response, and inhibition of the secretion of several hormones and neuropeptides (Munck et al. 1984). However, in response to long-term chronic stressors, all of these processes still occur but are prolonged, and thus the effects can become deleterious, causing steroid diabetes, infertility, inhibition of growth, and impaired resistance to disease. It is important to distinguish between chronic stressors that are reoccurring, predictable events in the life cycle of the organism from those that are not. An example of the former are the stressors associated with severe weather during the mating season of some birds, and to which a modulated or attenuated response has occurred (e.g., Wingfield et al. 1992, Silverin et al. 1997, Romero et al. 1998). An example of the latter is the stressor of high predation risk in snowshoe hares, which occurs during only a portion of the $10-y$ r cycle and results in a prolonged and deleterious stress response (Boonstra et al. 1998).

\section{Experimental protocol and predictions}

To assess the responsiveness of the HPA axis in arctic ground squirrels, we compared the ability of males to respond to a standardized challenge. We used a hormonal challenge protocol that permitted us to get an integrated picture of the squirrel's recent past while overriding the immediate stress response that the squirrel was experiencing because of the effects of capture and handling. This hormonal challenge protocol involved two steps: the dexamethasone suppression test (Kalin et al. 1981) followed by the adrenocorticotropic hormone (ACTH) stimulation test. The dexamethasone suppression test is a method to assess whether the brain is registering glucocorticoid levels correctly and making the necessary negative feedback adjustment by reducing ACTH and cortisol production. Dexamethasone is an artificial glucocorticoid that the brain registers as a mimic for the normal endogenous glucocorticoid. The ACTH stimulation test is a method to probe the responsiveness of adrenal glands directly. This protocol, or modifications of it, has been successfully applied in field studies on stress in a wide variety of species (e.g., deer, Smith and Bubenik 1990; sparrows, Astheimer et al. 1994; and snowshoe hares, Boonstra et al. 1998). We performed our comparison in males of three classes: adult breeding males in early May near the end of the mating period, adult nonbreeding males in early-to-late summer, and juvenile males in late summer when they had dispersed and were setting up new home ranges in competition with adult males.

We made the following predictions for differences among the three male classes. First, the chronic stress of activities related to mating results in adult breeding males with higher levels of free cortisol than males at other times. Chronic stress causes hypertrophy of the adrenal glands, resulting in an exaggerated response when stressed (see Miller and Tyrrell 1995). In addition, dexamethasone resistance should occur in adult breeding males (i.e., when dexamethasone is given, endogenous cortisol will not fall as rapidly in resistant animals as in normal ones, indicating that the feedback between the adrenals and pituitary is impaired). Dexamethasone resistance is characteristic of chronically stressed animals (e.g., Sapolsky 1983, McDonald et al. 1986, Bradley 1990). Second, the concentrations of the carrier protein for cortisol, corticosteroid-binding globulin (CBG), will decline if males are chronically stressed during the mating period, but not at other times. Chronic stressors of longer than 24 hours are known to cause CBG levels to decline in other mammals (Dallman et al. 1990, Armario et al. 1994, Fleshner et al. 1995). The bioavailability of circulating corticosteroids for target tissues is mediated by CBG, which acts as the carrier protein for cortisol. When bound to CBG, cortisol is biologically inactive (Siiteri et al. 1982, Rosner 1990) and, under basal conditions, 90-95\% of plasma glucocorticoids are bound to CBG. Thus, under conditions of the chronic stressor of intense mating competition in spring, CBG levels should be low and, as a result, free cortisol levels should be high when the animals are stressed. Third, we predict that breeding males should have a greater ability than other male classes to mobilize glucose from larger liver stores. Glucose is the critical fuel that sustains the energy demands of the body, and chronic stress will increase hepatic production and storage of glucose as glycogen by enhancing the liver's capacity for gluconeogenesis (Miller and Tyrrell 1995). Fourth, gluconeogenesis is achieved at the expense of peripheral tissues by changes at five levels: by decreasing their glucose uptake and utilization; by releasing gluconeogenic substrate from them; by increasing protein breakdown in several tissues such as muscle, adipose, and lymphoid; by decreasing protein synthesis; and by increasing energy substrate such as free fatty acids, FFA (Vander et al. 1990). FFA may also act directly as new gluconeogenic substrate by providing glycerol; Galster and Morrison (1975) indicate that in hibernating arctic ground squirrels, three-quarters of the glycogen produced during the period of homeothermy comes from 
fat. Our measure of the change in nonglucose energy stores is the ability to mobilize free fatty acids from fat deposits in response to the challenge. Fifth, although hematocrit (packed red blood cell volume) can change for a number of reasons, studies on wildlife have found that it is an indicator of body condition in which higher values have been linked to better condition (Franzmann and LeResche 1978, Lochmiller et al. 1986, Hellgren et al. 1993, Boonstra et al. 1998). Thus, if adult breeding males are chronically stressed and in poorer condition, we expect their hematocrit to be lower. Finally, chronic stress should produce higher levels of free cortisol, which should act as an immunosuppressant (Keller et al. 1984, Munck et al. 1984, Kelley 1985). Increased cortisol should result in lower levels of white blood cells and in a decreased ability to mount an immune response to an antigen challenge.

\section{Biology of arctic ground squirrels}

Because our experiments were done at critical stages in the active life of males, it is necessary to appreciate their basic biology and the sequence of events in their yearly life cycle. Arctic ground squirrels are found throughout the tundra and alpine areas of mainland Canada, into the boreal forests of northwestern Canada, and throughout Alaska (Banfield 1974). They are obligate hibernators, emerging above ground from a 7-8 month hibernation in early-to-mid-April, with males appearing 1-2 weeks before females (Carl 1971, Lacey 1991, Buck and Barnes 1999a, b). Mating occurs within 3-4 days of female emergence and is generally highly synchronous (usually being completed within a 2-3 week period) and promiscuous, with many litters being multiply sired (Lacey et al. 1997). Virtually all yearlings are reproductively mature and, thus, almost the entire population breeds each year. Gestation lasts 25 days, and young appear above ground 27 days after birth, in late June-early July (Lacey 1991, Hubbs and Boonstra 1997). Surviving postreproductive adult males disperse from the site of reproduction in July, probably to avoid mating with their daughters the next spring (Hoogland 1982, Holekamp and Sherman 1989). Juvenile females are philopatric and remain near their mothers, whereas juvenile males disperse in mid-tolate July (Byrom and Krebs 1999, Byrom et al. 2000). Dispersing juvenile males suffer much higher mortality rates than the philopatric juvenile females (Byrom and Krebs 1999); this partially explains the female-biased sex ratio in these populations. Immediately after dispersal in summer, the priority for both adult and juvenile males is to establish a new territory with a hibernaculum near females, in anticipation of the mating period the next year, and to forage to acquire sufficient mass to survive hibernation. Some aggression among males occurs at that time (Carl 1971, Green 1977). Adult females usually enter hibernation in late July to mid-August, followed by juvenile females and adult males in late August-September, and finally by juvenile males as late as in early October (McLean 1981).

\section{MeTHODS \\ Study area}

The study was conducted near the Arctic Institute Base at Kluane Lake, Yukon Territory, Canada $\left(60^{\circ} 57^{\prime}\right.$ $\mathrm{N}, 138^{\circ} 12^{\prime} \mathrm{W}$ ), at $900 \mathrm{~m}$ elevation (Boutin et al. 1995, Krebs et al. 1995). This site is within the boreal forest region of North America and was the location of a longterm study (1986-1996) of community dynamics in the boreal forest (the Kluane Boreal Forest Ecosystem Project; Krebs et al. 1995). The boreal forest surrounding this site is heterogeneous, dominated by white spruce (Picea glauca) forests with an understory of willow (Salix spp.) and birch (Betula glandulosa), willow shrub thickets, grass meadows, and aspen poplar (Populus tremuloides) stands. The climate is cold continental, with the growing season lasting from mid-May through to mid-August and snow cover occurring from October through early May.

\section{Trapping procedures}

Squirrels were trapped in Tomahawk live traps baited with peanut butter $(14 \times 14 \times 40 \mathrm{~cm}$ or $16.5 \times 16.5$ $\times 48 \mathrm{~cm}$; Tomahawk Live Trap Company, Tomahawk, Wisconsin, USA), tagged with monel \#1005-1 tags (National Band and Tag Company, Newport, Kentucky) in both ears, weighed, and sexed. Trapping occurred on $\sim 9$-ha grids containing 100 trap points spaced 30 $\mathrm{m}$ apart and arranged in a $10 \times 10$ array (for descriptions of the sites, see Hubbs and Boonstra 1997, Karels et al. 2000). Traps were placed only at burrow sites to increase recaptures of individuals. Two or three traps were placed at burrow systems that had at least three burrow openings. Two intensive censuses $(4 \mathrm{~d}$ each) occurred: in spring (the first two weeks of May) to obtain overwinter survival, and in late summer (the last two weeks of July) to obtain density after reproduction and juvenile recruitment prior to hibernation. Data were supplemented in 1994 with trapping every 2 wk for $2 \mathrm{~d}$ on each grid to follow reproductive and body mass changes, and with intense trapping in midto-late June to capture emerging juveniles. For censuses, traps were set at 0700 , checked three times at 1.5-h intervals, and closed at 1230. At other times, traps were set at 0830, checked twice at 1.5 -h intervals, and closed at 1230 . We pooled all grids and calculated the minimum number alive each week (the number of squirrels caught at time $t$ plus those not caught but known to be present because of captures before and after time $t$ ).

To assess how the adult breeding male population was affected by reproduction, we carried out two analyses. First, we determined how the ratio of males to females changed in spring by examining the trapping data collected from a representative year (Hubbs and 
Boonstra 1997, Byrom et al. 2000, Karels et al. 2000). During 1994, we were able to be at the Kluane site the earliest of any of the springs ( $31 \mathrm{March}$ ), and thus have a more complete picture from this year of the emergence patterns and changes in numbers of males and females. We pooled the data from six trapping grids (Control A and C, Food 1 and 2, Predator Exclosure, and Predator Exclosure + Food) to increase sample size and because a similar yearly sequence of changes occurred in demography and social organization on all grids (Byrom et al. 2000, Karels et al. 2000).

Second, we calculated survival of males and females immediately after breeding to examine whether the rigors of breeding had a differential impact. Surviving males that have bred remain near the females with which they have bred, show territorial behavior (possibly to protect their offspring from other males), and do not disperse to a new site until late June and July after the young have been weaned in mid-June (Carl 1971, McLean 1981, 1983, Lacey 1991). Thus, disappearance between the end of breeding in early May and mid-June most probably indicates that the animal has died. We determined how many of males and females that were present on the trapping grids in the last week of April and the first week of May (the end of the mating period) from 1994 to 1997 were still present in the population in mid-June. The previously described grids were used (but only controls in 1996 and 1997, as termination of experimental treatments in spring 1996 had marked effects on squirrel demography). Grids were eliminated if no males were trapped during that period or if the grid was not trapped during that period. All grids were pooled because of low sample size on some of them during this period. We used a $G$ test to assess the difference in the percentage of males and females surviving; the Jolly estimate of survival could not be used because of low sample sizes in most of these populations.

\section{Experimental animals}

Males for the experiment were collected in 1996 within $15 \mathrm{~km}$ of the Arctic Institute Base in the meadows and grassy roadside margins adjacent to the Alaska Highway and the old Alaska Highway; none were from the livetrapping grids just described. We used three categories of males ( $N=10$ in each): adult breeding, adult nonbreeding, and juvenile nonbreeding. Adult breeding males (both yearlings and $>1 \mathrm{yr}$ old, with enlarged testes descended into a dark scrotum) were trapped from 2 to 4 May; adult nonbreeding males ( $\geq 1$ yr old, with small, nondescended testes) were trapped from 24 June (four males) and from 7 to 12 August (six males); and juvenile males (young-of-the-year, with small, nondescended testes) were trapped from 12 to 16 August. We recognize that some of those classified as adult nonbreeding may have been yearlings that had not bred in spring. A small number of males remain nonreproductive during the spring breeding pe- riod. These are young males that have overwintered on or near their natal territory (Lacey 1991) and subsequently disperse in spring after the mating period. In our populations in 1994, these nonbreeders constituted $8 \%$ of the male population $(N=52$, all grids combined; T. J. Karels, unpublished data). These nonbreeders grow rapidly in spring and become indistinguishable, in terms of size, by summer (Lacey 1991, Buck and Barnes 1999a). Adult nonbreeding males (658.5 \pm 18.4 $\mathrm{g}$, mean $\pm 1 \mathrm{SE})$ were over $150 \mathrm{~g}$ heavier $(F=30.2$, df $=2,27, P<0.0001)$ than adult breeding males $(454.0 \pm 10.7 \mathrm{~g})$ and juvenile males $(493.5 \pm 26.8 \mathrm{~g})$.

Males were captured in Tomahawk live-traps baited with peanut butter and set adjacent to burrows. Traps were set between 0800 and 0930 and were checked hourly. Thus, males were in the traps for no more than 60 min before being collected, but we did not know exactly when they entered the trap. All males were weighed and aged based on size and testes condition. Breeding males were transported by vehicle to a dimly lit, quiet laboratory at the Kluane Lake Base, remaining in traps covered in burlap to avoid prolonged exposure to the cold temperatures of early May. They were allowed to habituate to the laboratory surroundings for $\sim 1.5 \mathrm{~h}$ before they were subjected to the stress challenge. Nonbreeding and juvenile males were collected along the roadways and transported by vehicle to a centralized field site where the challenge experiment was performed after an habituation period of $\sim 1.5 \mathrm{~h}$; all were covered with burlap to minimize visual contact with us or with other animals. The males were then transported to the Arctic Institute Base for immunocompetence tests.

\section{Hormonal challenge protocol}

All animals were anesthetized prior to the collection of blood samples, using the inhalant anesthetic metofane (methoxyflurane) at an approximate concentration of $4 \%$ using the bell-jar technique (McColl and Boonstra 1999). Animals were anesthetized in 30-90 s and blood samples were collected within 1 min of anesthesia being induced. Each squirrel was bled five times by suborbital sinus puncture. Blood from the first sample (called the BASE bleed, $\sim 500 \mu \mathrm{L}$ ) was used to obtain baseline estimates of blood parameters. Immediately following the BASE bleed, animals were injected with $0.4 \mathrm{mg} / \mathrm{kg}$ dexamethasone sodium phosphate (Sabex, Montreal, Canada) by cardiac puncture as recommended by B. Barnes (University of Alaska, Fairbanks, Alaska, USA). The second blood sample (called the DEX bleed, $300 \mu \mathrm{L}$ ) was collected $2 \mathrm{~h}$ after the dexamethasone injection and was immediately followed by an intramuscular injection into the thigh of $4 \mathrm{IU} / \mathrm{kg}$ of synthetic ACTH (Synacthen Depot, CIBA, Ontario, Canada). Subsequent blood samples were collected at 30,60, and $120 \mathrm{~min}$ post-ACTH injection (called the P30, P60, and P120 bleeds, respectively; all samples were $300 \mu \mathrm{L}$ ). Amounts of DEX and ACTH 
injected were determined based on the body masses obtained when the males were trapped. These procedures follow Canadian Council of Animal Care guidelines and were approved under a University of Toronto Animal Use Protocol.

\section{Hematology}

Blood samples were collected in heparinized $75-\mu \mathrm{L}$ microhematocrit tubes (Red-Tips: Fisher Scientific, Pittsburgh, Pennsylvania, USA) and were allowed to flow into $0.5-\mathrm{mL}$ vials. Blood samples were stored on ice in the field. Measurement of glucose concentrations was generally completed within $5 \mathrm{~min}$, and always within $15 \mathrm{~min}$ of blood collection. Hematology was conducted only on the first bleed of each animal, except for glucose concentrations and fatty acid concentrations, which were measured for every bleed. Glucose concentrations $(\mathrm{mg} / \mathrm{dL})$ were measured by glucose oxidase/peroxidase reaction (Accu-chek III, MannheimBoehringer, Mannheim, Germany). The accuracy of the device was compared with standard control solutions and the values were within $20 \%$ for the low control solution $(51 \mathrm{mg} / \mathrm{dL})$ and $10 \%$ for the high control solution $(292 \mathrm{mg} / \mathrm{dL})$; these are within the admissible range as indicated by the manufacturer. Hematocrit was measured as the packed red blood cell volume in 75$\mu \mathrm{L}$ heparinized microhematocrit tubes sealed with Critoseal (Oxford Labware, St. Louis, Missouri, USA). Hematocrit was measured on two samples per squirrel after a 5-min centrifugation at $13460 \mathrm{~g}$ on an IEC Micro-Hematocrit Centrifuge, Model MB (Needham Heights, Massachusetts, USA) upon our return to the field station. Two blood smears for identification and quantification of white blood cell type were made from the baseline sample of each animal. The smears were fixed and stained with a modified Wright Stain technique using Diff-Quik (Baxter Health Care, Miami, Florida, USA). All white blood cell counts were carried out by two people and differential counts were based on identification of 100 leucocytes. The remaining blood was centrifuged at $8800 \mathrm{~g}$ for $8 \mathrm{~min}$ in an Eppendorf Micro Centrifuge (Eppendorf, Hamburg, Germany). The separated plasma was frozen at $-20^{\circ} \mathrm{C}$ until transported to Toronto, where it was stored at $-70^{\circ} \mathrm{C}$ until analysis. In Toronto, hormone assays and total free fatty acids (FFA) were measured. FFA was measured by the method of Laurell and Tibbling (1967). To obtain adequate levels of FFA, $25 \mu \mathrm{L}$ of plasma were extracted.

\section{Hormone assays}

We measured total plasma cortisol by the radioimmunoassay method used by Boonstra and Singleton (1993), using anti-cortisol antibody A-155 obtained from Western Chemical (Fort Collins, Colorado, USA). The antiserum shows the following cross-reactivities: corticosterone, $1.4 \%$; cortisone, $1.6 \%$; deoxycorticosterone, $1.3 \%$; progesterone, $1.0 \%$; and estradiol, es- triol, and estrone, $<0.1 \%$. All reagents were redistilled. We added $40 \mu \mathrm{L}$ double-distilled water and $20 \mu \mathrm{L}$ $\mathrm{NH}_{4} \mathrm{OH}$ (to saponify triglycerides) to duplicate $10-\mu \mathrm{L}$ samples of plasma. We added $2 \mathrm{~mL}$ dichloromethane (Fisher) to the washed plasma, which were then vortexed and centrifuged at $1000 \mathrm{rpm}$, and the aqueous layer was aspirated. One $400-\mu \mathrm{L}$ sample of the dichloromethane extraction mixture was removed, transferred to a new tube, dried in a $37^{\circ} \mathrm{C}$ water bath under nitrogen, and $300 \mu \mathrm{L}$ of phosphate buffer ( $\mathrm{pH} 7)$ were added and allowed to equilibrate at room temperature for $1 \mathrm{~h}$. The reconstituted extract was incubated with $100 \mu \mathrm{L}$ antibody and $100 \mu \mathrm{L}\left[1,2,6,7-{ }^{3} \mathrm{H}\right]$ cortisol (Amersham), and dextran-coated charcoal was used to separate bound and free hormone. Values of charcoalstripped plasma and of solvent did not differ significantly from zero. The assay was sensitive to $10 \mathrm{pg} / 10$ $\mu \mathrm{L}$. The recovery of $\left[1,2,6,7-{ }^{3} \mathrm{H}\right]$ cortisol added to plasma was $105 \pm 1.2 \%$, mean $\pm 1 \mathrm{SE}$ (range 100-107\%). The intra- and interassay coefficients of variation were $6 \%$ and $11 \%$, respectively.

Critical to understanding the potential impact of changing cortisol levels is knowing how much cortisol is actually free and not bound to its main carrier protein, corticosteroid-binding globulin (CBG). It is primarily the free cortisol that appears to be biologically active (Rosner 1990). Thus, it is critical to determine how much plasma cortisol is free as opposed to the total cortisol present. CBG, however, does not simply appear to act as a buffering mechanism for cortisol in plasma, but also acts as a carrier protein for cortisol, interacting with cell surface receptors, and it may also be internalized in the cell (Rosner 1990). We calculated the concentrations of free cortisol using the calculation procedures outlined in Tait and Burstein (1964). For these calculations, we needed to know three values: the albumin concentration in plasma (albumin also binds cortisol and has high capacity but low affinity), the ratio of albumin-bound to free cortisol, and the affinity constant of CBG for cortisol. Pure albumin was obtained through the trichloroacetic acid method described in Michael (1962). This albumin was then used as a standard to calculate the concentration of albumin in plasma by the chromographic method of Debro et al. (1957). We calculated that arctic ground squirrels have $2.54 \mathrm{~g}$ albumin/100 $\mathrm{mL}$ plasma, and used this in all our calculations of free cortisol. Although ablumin levels can vary because of factors such as nutrition and stress (Peters 1996), albumin has low affinity for cortisol relative to $\mathrm{CBG}$ (the latter binding cortisol $\sim 6000$ times more strongly, than albumin; e.g., Sandberg and Slaunwhite 1959). Thus, slight variation in albumin levels should not have major influences on the amount of cortisol that is free (Tait and Burstein 1994). The ratio of albumin-bound to free cortisol in a $1 \%$ solution was 0.19:1.0. This value was obtained using the dialysis method described in Paterson and Hills (1967). The CBG affinity constant for squirrels was measured 
in a microdialysis system (Englund et al. 1969) modified to 12 chambers (A. J. Bradley, personal communication) using $60-\mu \mathrm{L}$ samples of plasma diluted 1 : 5 with a phosphosaline buffer $(0.05 \mathrm{~mol} / \mathrm{L}, \mathrm{pH} 7.4)$. In this system, equilibrium was established in $12 \mathrm{~h}$ at $37^{\circ} \mathrm{C}$, following which the specific activity of dialysate and sac contents was measured in a scintillation counter. The concentration of CBG-bound and unbound cortisol was calculated by the method described in Paterson and Hills (1967) and the CBG affinity constant was calculated by the Scatchard analysis (Scatchard 1949). We calculated the CBG-binding constant to be $4.505 \times 10^{7} \mathrm{~L} / \mathrm{mol}$.

Plasma corticosteroid-binding globulin (CBG) was measured as the maximum corticosteroid-binding capacity (MCBC). We followed the technique of Doe et al. (1964), which was simplified by use of dextrancoated charcoal to separate free from bound steroid (for details of the modification, see McDonald et al. 1981). To each plasma sample, we added $\left[1,2,6,7-{ }^{3} \mathrm{H}\right]$ cortisol (Amersham) and cold cortisol to known specific activity five- to 20-fold in excess of the expected capacity. We allowed for the contribution of endogenous cortisol in the sample. The high-affinity fraction in a $10-\mu \mathrm{L}$ sample of plasma, diluted in $0.5 \mathrm{~mL}$ phosphate buffer, was measured by liquid scintillation after separation from the free- and albumin-bound fractions with dextran-coated charcoal. The high-affinity bound cortisol was then calculated knowing the specific activity and the radioactivity in the bound fraction.

Plasma testosterone plus dihydrotestosterone was measured by radioimmunoassay. The antibody (P43/ 11), produced by Croze and Etches (1980), showed a major cross-reaction to dihydrotestosterone (62\%) relative to testosterone. The protocol for the radioimmunoassay of testosterone was based on that of Abraham et al. (1971), with double diethyl ether extractions of duplicate plasma samples (for a description of the method, see Boonstra and Boag 1992). Prior to extraction, each plasma sample $(25 \mu \mathrm{L})$ was treated with $20 \mu \mathrm{L} \mathrm{NH} \mathrm{N}_{4} \mathrm{OH}$ to saponify triglycerides. Two qualitycontrol samples were run in duplicate with each assay. Blank values of solvents were also run with each assay and did not differ significantly from zero. The assay was sensitive enough to detect $10 \mathrm{pg}$ testosterone per $25 \mu \mathrm{L}$ plasma. The intra- and interassay coefficients of variation for testosterone were $5 \%$ and $6 \%$, respectively.

\section{Immunocompetence challenge}

Immunological competence was measured by challenging the animals with a single subcutaneous injection of $0.4 \mathrm{~mL} / \mathrm{kg}$ of a $50 \%$ suspension of sheep red blood cells in a saline suspension (for the general protocol, see Bradley 1987). A blood sample was collected $7 \mathrm{~d}$ after the injection and was allowed to clot for 90 min at room temperature, and then overnight at $4{ }^{\circ} \mathrm{C}$. Sera were separated by centrifugation and stored at $-20^{\circ} \mathrm{C}$ until they were transported to Toronto, where they were stored at $-70^{\circ} \mathrm{C}$ until analysis. Between injection and blood sampling, the animals were held in outdoor cages and were provided with shelter for sleeping and cotton for warmth. The animals were fed commercial rabbit chow ad libitum and were provided with fresh apple and peanut butter daily. The diet was supplemented with fresh vegetation normally found in their diet, when available.

In the lab in Toronto, sera were heat-activated at $56^{\circ} \mathrm{C}$ for $30 \mathrm{~min}$ and were then tested immediately for antibody activity. Antibodies to sheep red blood cells were detected by macroscopic hemagglutination tests on microscope slides. We gently shook $10 \mu \mathrm{L}$ of plasma, $10 \mu \mathrm{L}$ of sheep red blood cells diluted 1:10 with phosphate buffer saline (PBS), and $20 \mu \mathrm{L}$ of PBS on a slide for $3 \mathrm{~min}$, and then determined the degree of agglutination. Serial dilutions were made until no agglutination was detected.

\section{Statistical analysis}

Data were expressed as means \pm 1 SE. We used Cochran's test (Winer 1971), as recommended by Day and Quinn (1989), to test for homogeneity of variance. The hormone, glucose, FFA, and reciprocal titre data did not meet the assumption of homogeneous variances, and we used the $\log (x+1)$ transformation to make the variances homogeneous. All ANOVAs were performed using SuperANOVA (Gagnon et al. 1990). A repeated-measures ANOVA was carried out on squirrels that were hormonally challenged. We used the conservative Greenhouse-Geisser epsilon to adjust the degrees of freedom before calculating the probabilities, as recommended by Keppel (1982). We used the TukeyKramer multiple comparison post hoc test to examine the significance of main effects. All other statistical tests were performed according to procedures in Zar (1984) and Sokal and Rohlf (1995).

Back in Toronto, upon analyzing the plasma for hormone levels, we discovered that the ACTH had denatured for some of the injections occurring in summer (the spring sampling of breeding males was not affected). This was inferred because of the lack of a rapid increase in cortisol levels after ACTH injection, whereas in $\sim 200$ other animals challenged in this manner for other reasons, we have always observed an immediate and rapid cortisol increase (McColl 1998). This most likely occurred because the refrigerator in which the ACTH was kept had malfunctioned, heating up the stock solution. As a consequence, the results of the plasma samples for the post-ACTH bleeds for six adult nonbreeding males and five juvenile nonbreeding males had to be discarded. However, this did not affect the results of the BASE and DEX bleeds and, hence, these were still valid. Consequently, the repeated-measure ANOVA was done on sample sizes of 10 , four, and five for adult breeding, adult nonbreeding, and juvenile males, respectively. However, in all statistical analyses 


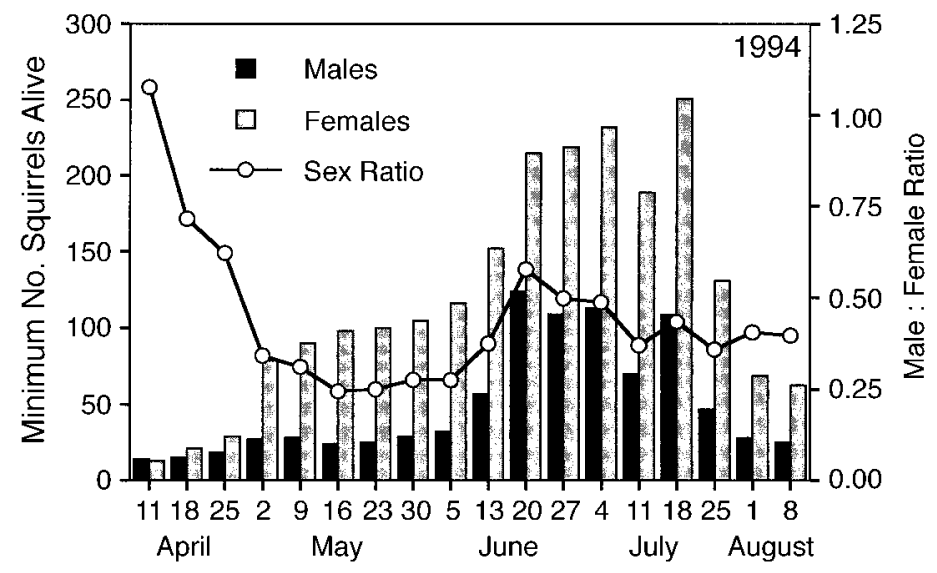

FIG. 1. Changes in the number of male and female arctic ground squirrels trapped in 1994 from the pooled data of six live-trapping grids, as part of the Kluane Boreal Forest Ecosystem Project, Yukon (Boutin et al. 1995, Byrom et al. 2000, Karels et al. 2000), and the changing ratio of males to females over this summer. that examine only the BASE or DEX samples, and in all of the figures presenting the BASE and DEX samples, the full data set is presented for each male class.

\section{RESULTS}

\section{Male :female population changes}

The ratio of males to females changed markedly in 1994 (Fig. 1). In the first capture week in mid-April, the ratio was $\sim 1: 1$, but thereafter the proportion of males in the population rapidly declined. By the first week in May and over much of the remaining spring, the ratio was about $1: 3$ (i.e., $25-30 \%$ of the population was male). After the juveniles started entering the population from 13 to 19 June, the ratio was $\sim 1: 2.5$. Part of this shift in sex ratio in late spring was the later emergence of large numbers of females, but part was also related to the differential disappearance of males from the population. Of the overwintering males captured until 8 May $(N=29)$, $48 \%$ were not trapped again. Of those captured at least twice from 11 April to 8 May, males lost an average of $9.90 \pm 1.76 \mathrm{~g} / \mathrm{d}$ (range $2.50-21.43 \mathrm{~g} / \mathrm{d}, N=11$ ).

For all years and grids pooled, only $42.1 \%(N=57)$ of the breeding males present in the last week of April to the first week of May were still present in mid-June, in contrast to $74.3 \%(N=152)$ of the females $(G=$ $18.48, P<0.0001)$. This difference in survival on the grid was similar across years. Only 1994 and 1995 had sufficient sample sizes to be analyzed by themselves. In $1994,45 \%(N=20)$ of the males survived vs. $72.7 \%$ $(N=66)$ of the females $(G=5.06, P<0.02)$; in 1995 , the values were $40.5 \%(N=31)$ and $75.6 \%(N=65)$ ( $G=13.64, P<0.0002)$, respectively. Thus, over half of the breeding males disappeared from the population shortly after the mating period, in comparison with about a quarter of the females. However, from this analysis it cannot be determined whether the loss of breeding males was caused by death or by dispersal.

If dispersal explains the loss, then males within the entire area should simply be reshuffling their sites of residency, and the total number within a local area should not change (i.e., emigration should equal immigration; for a similar analysis in voles, see Krebs and Boonstra 1978). To test this assumption, we examined the trapping records on the grids for 1994 and 1995 to determine how many of the disappearing males that had been resident and scrotal during or after the mating period were replaced by new untagged males moving into the trapped population. We included only the period up until mid-June, because thereafter, all surviving resident, adult males disperse to new sites as their offspring have been weaned and appear above ground (McLean 1983, Lacey 1991). From April through to 19 June 1994, 19 adult males disappeared and were replaced by one immigrant male; respective values in 1995 were 32 and 8 adult males. Thus, for those males that disappear during this time period, most $(82.3 \%)$ are not replaced by new males. Therefore, we estimate that, overall, $47.6 \%$ of the males were lost from the population by death $(57.9 \%$ disappearing from their grid of capture $\times 82.3 \%$ not being replaced by immigrants).

\section{Plasma cortisol levels}

To assess how free cortisol levels changed, we present three analyses: first, we analyzed how BASE levels differed among the males, as these samples would represent their responses to trapping and handling; second, we present the overall group average response of the squirrels to the challenge test, which represents the between-group main effect; and third, we present the within-subjects effects showing how the levels varied over time as a function of the injections. At BASE, there were no significant differences in free cortisol levels among the males $(F=0.72$, df $=2,27, P=$ $0.50)$. The repeated-measures ANOVA indicated that, averaged over the entire experiment (after the removal of variance owing to within-subject effects), there was a significant difference among males (Table 1). Free cortisol levels were $>20 \%$ higher in adult breeding males than in adult nonbreeding and juvenile males. The within-subjects effects examining the responses to 
TABLE 1. Average effects (means $\pm 1 \mathrm{SE})$ of the hormonal challenge on adult breeding $(N=$ 10 , collected 2-4 May), adult nonbreeding ( $N=4$, collected 24 June), and juvenile male $(N=5$, collected 12-16 August) arctic ground squirrels in 1996.

\begin{tabular}{lccc}
\hline \hline \multicolumn{1}{c}{$\begin{array}{c}\text { Blood } \\
\text { component }\end{array}$} & $\begin{array}{c}\text { Adult } \\
\text { breeding }\end{array}$ & $\begin{array}{c}\text { Adult } \\
\text { nonbreeding }\end{array}$ & Juvenile \\
\hline Free cortisol $(\mathrm{ng} / \mathrm{mL})^{* *}$ & $63.5^{\mathrm{a}} \pm 5.6$ & $45.8^{\mathrm{b}} \pm 6.8$ & $52.6^{\mathrm{b}} \pm 6.0$ \\
MCBC $(\mathrm{ng} / \mathrm{mL})^{*} * *$ & $84.9^{\mathrm{a}} \pm 2.7$ & $264.0^{\mathrm{b}} \pm 6.5$ & $191.7^{\mathrm{b}} \pm 9.5$ \\
Testosterone $(\mathrm{ng} / \mathrm{mL})$ & $8.6 \pm 0.4$ & $9.7 \pm 0.5$ & $6.8 \pm 0.4$ \\
Glucose $(\mathrm{mg} / \mathrm{dL})^{*}$ & $108.7^{\mathrm{a}, \mathrm{c}} \pm 4.6$ & $92.0^{\mathrm{a}, \mathrm{b}} \pm 4.2$ & $134.4^{\mathrm{c}} \pm 3.6$ \\
Free fatty acids $(\mathrm{ng} / \mathrm{mL})^{*}$ & $141.0^{\mathrm{a}} \pm 10.2$ & $212.8^{\mathrm{b}} \pm 20.5$ & $156.4^{\mathrm{a}} \pm 28.2$ \\
\hline
\end{tabular}

Note: Means with the same superscript letters are not significantly different.

$* P<0.05$, ** $P<0.01$, *** $P<0.0001$.

the injections over the time course of the experiment were significant for free cortisol, but these effects are complicated by interaction effects (Table 2). All male classes showed a marked decline in free cortisol in response to DEX, dropping to $<6 \%$ of BASE levels, indicating that the negative feedback effect of glucocorticoids was being registered by the brain. However, there was slight evidence of dexamethasone resistance in adult breeding males, as they maintained significantly higher free cortisol levels at the DEX bleed (3.1

TABLE 2. Repeated-measures ANOVA testing differences among the three classes of male arctic ground squirrels in response to the hormonal challenge protocol.

\begin{tabular}{|c|c|c|c|c|}
\hline Source & df & MS & $F$ & $P$ \\
\hline \multicolumn{5}{|l|}{ Free cortisol } \\
\hline Treatment & 2 & 0.205 & 6.4 & 0.009 \\
\hline Subject (Group) & 16 & 0.032 & & \\
\hline Time & 4 & 7.110 & 374.2 & 0.0001 \\
\hline Time $\times$ Treatment & 8 & 0.050 & 2.7 & 0.01 \\
\hline Error & 64 & 0.019 & & \\
\hline \multicolumn{5}{|l|}{ MCBC } \\
\hline Treatment & 2 & 2.167 & 74.9 & 0.0001 \\
\hline Subject (Group) & 16 & 0.029 & & \\
\hline Time & 4 & 0.003 & 0.9 & \\
\hline Time $\times$ Treatment & 8 & 0.002 & 0.5 & \\
\hline Error & 64 & 0.004 & & \\
\hline \multicolumn{5}{|l|}{ Testosterone } \\
\hline Treatment & 2 & 0.119 & 1.7 & \\
\hline Subject (Group) & 16 & 0.072 & & \\
\hline Time & 4 & 0.053 & 14.8 & 0.0001 \\
\hline Time $\times$ Treatment & 8 & 0.004 & 1.0 & \\
\hline Error & 64 & 0.004 & & \\
\hline \multicolumn{5}{|l|}{ Glucose } \\
\hline Treatment & 2 & 0.170 & 3.8 & 0.04 \\
\hline Subject (Group) & 16 & 0.045 & & \\
\hline Time & 4 & 0.014 & 2.5 & 0.08 \\
\hline Time $\times$ Treatment & 8 & 0.017 & 3.1 & 0.02 \\
\hline Error & 64 & 0.006 & & \\
\hline \multicolumn{5}{|l|}{ Free fatty acids } \\
\hline Treatment & 2 & 0.040 & 4.3 & 0.03 \\
\hline Subject (Group) & 16 & 0.009 & & \\
\hline Time & 4 & 0.050 & 9.6 & 0.0002 \\
\hline Time $\times$ Treatment & 8 & 0.013 & 2.4 & 0.05 \\
\hline Error & 64 & 0.005 & & \\
\hline
\end{tabular}

Notes: The probability estimates of the within-subject (time) analysis were adjusted using the Greenhouse-Geisser estimate. All absent probability values are nonsignificant, but those just above significance are also given. $\pm 0.5 \mathrm{ng} / \mathrm{mL}$ ) than did either adult nonbreeding males $(2.0 \pm 0.4 \mathrm{ng} / \mathrm{mL})$ or juvenile males $(1.0 \pm 0.1 \mathrm{ng} /$ $\mathrm{mL}$ ) (one-way ANOVA: $F=13.21, \mathrm{df}=2,27, P<$ $0.0001)$. All male classes showed a marked and rapid increase in free cortisol in response to ACTH, indicating that the adrenal glands were also responding as they should (Fig. 2). The response in both adult breeding males and juveniles was most dramatic, with levels at $\mathrm{P} 30$ exceeding those at the BASE bleed and reaching

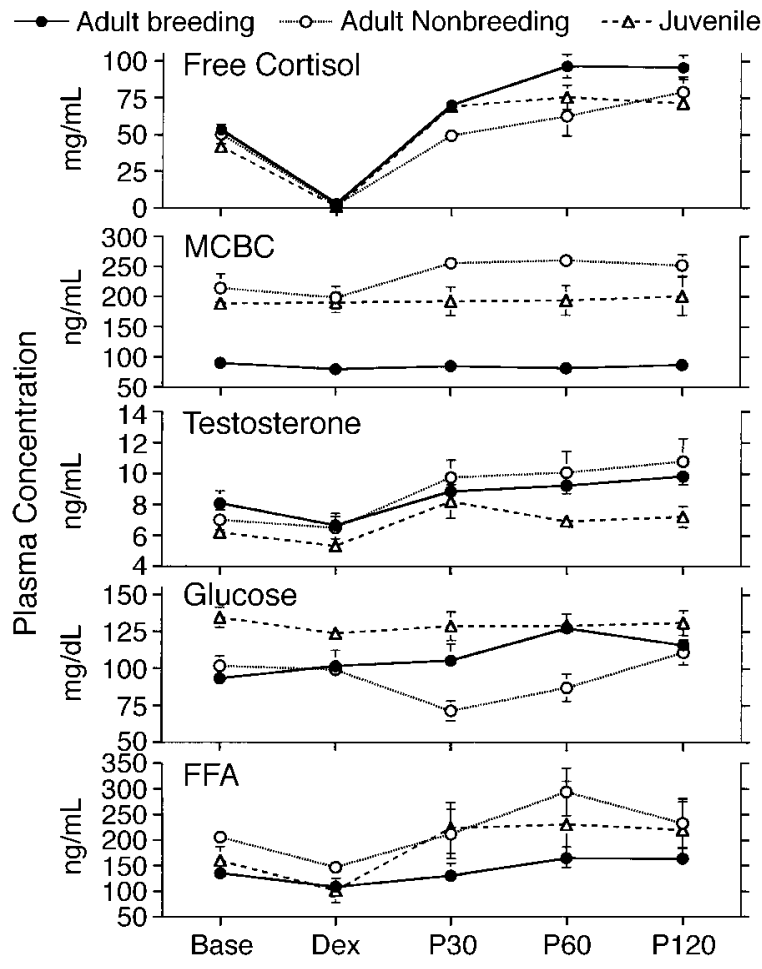

FIG. 2. Responses over time in plasma concentrations of various parameters in male arctic ground squirrels from the Yukon. BASE bleeds indicate values at the initial bleed, DEX indicates values $2 \mathrm{~h}$ after the dexamethasone injection, and P30, P60, and P120 indicate values 30, 60, and $120 \mathrm{~min}$, respectively, after the adrenocorticotropic hormone (ACTH) injection. Errors bars ( $\pm 1 \mathrm{SE})$ are presented for all means, and for those that are not visible, the error bar is small and hidden by the size of the symbol. Abbreviations: MCBC, maximum corticosteroid binding capacity; FFA, free fatty acids. 
their highest levels at P60 (levels $80 \%$ higher than those at the BASE bleed). At P30, levels in adult nonbreeding males were the same as those at the BASE bleed; at P60, they were $24 \%$ higher than those at the BASE bleed. Thereafter, levels to P120 stabilized in both adult breeding males and juvenile males, but continued to increase in adult nonbreeding males; hence, these differences explain the interaction effect (Table 2). Although the overall pattern was roughly similar among the three classes, adult breeding males had higher levels of free cortisol overall and responded less to the DEX injection; both adult breeding males and juvenile males responded more dramatically to the ACTH injection within the first hour than did adult nonbreeding males.

The maximum corticosteroid-binding capacity (MCBC) was constant over the length of the experiment in all three classes of males (Fig. 2, Table 2). However, levels in adult breeding males were significantly lower than in the other two male classes, being only about one-third that of adult nonbreeding males (Table 1). Thus, the plasma of adult breeding males had a much more limited ability to buffer them from the effects of high levels of cortisol released in response to a stressor.

\section{Energy mobilization}

At BASE, juveniles had significantly higher glucose levels than either of the adult male classes $(F=8.87$, df $=2,27, P=0.001$; Fig. 2). In response to the injections, no consistent pattern in glucose response emerged among the three classes of males. The repeated-measures ANOVA indicated that, averaged over the entire experiment, juveniles had significantly higher glucose levels than adult nonbreeding males $(46 \%$ more), but levels similar to those of adult breeding males (Table 1). The within-subjects effects examining the responses to the injections over time indicated that there was no change in glucose levels with time, but this was complicated by a significant interaction effect (Table 2). Levels in juvenile males remained remarkably constant and high, independent of the injections (Fig. 2). Levels in both classes of adult males showed no response to the DEX injection. In response to ACTH, levels in breeding males increased until P60 and then declined slightly, whereas levels in nonbreeding males fell until P30 and then increased until P120. Thus, in general, adult breeding and nonbreeding males were significantly less able to mobilize glucose than were juveniles (Fig. 2), but no clear pattern emerged in response to the injections of DEX and ACTH.

At BASE, FFA levels in adult nonbreeding males were significantly higher than those in adult breeding males, but were not different from those in juvenile males $(F=3.91$, df $=2,25, P=0.03$; Fig. 2$)$. Two males had insufficient plasma at the base bleed and, hence, the sample was reduced. The repeated-measures ANOVA indicated that, averaged over the entire experiment, adult nonbreeding males had significantly higher FFA levels than either adult breeding males or juvenile males (34\% and $26 \%$ higher, respectively; Table 1). The within-subjects effects examining responses to the injections over time indicated that there was a significant change in FFA levels with time, but the significant interaction effect indicates that the intensity of the response varied among male classes. In response to the DEX injection, FFA levels fell in all male classes (a decline of $28.5 \%$ for the whole data set; Fig. 2). In response to the $\mathrm{ACTH}$ injection, FFA levels increased in all male classes, with the response being modest in adult breeding and adult nonbreeding males (an increase by $\mathrm{P} 30$ of $20 \%$ and $45 \%$, respectively) and large in juvenile males (120\% increase by P30). Thus, FFA levels differed among the male classes, with levels being highest overall in adult nonbreeding males, and, although all responded to the injections (declining with DEX, increasing with ACTH), the intensity of the response varied among the three classes.

\section{Plasma testosterone levels}

Testosterone levels showed no difference among the male classes, either at the BASE bleed $(F=1.8$, df $=$ $2,27, P<0.19$ ) or over the rest of the experiment (Tables 1 and 2). However, the within-subjects effects of the repeated-measures ANOVA indicated that testosterone levels changed significantly over time (Table 2 ), with levels falling $\sim 13 \%$ after the DEX injection and then increasing to $\sim 25 \%$ above BASE levels in response to the $\mathrm{ACTH}$ injection, remaining at these levels for the remainder of the experiment (Fig. 2). To examine whether there were age differences independent of breeding condition, we separated the data into adults vs. juveniles. Again, there was no overall difference over the entire experiment $(F=2.70$, df $=1$, $17, P=0.12)$. Thus, reproductive condition had no effect on testosterone levels in males, and the age effect was not strong. All males responded to the artificial glucocorticoid, DEX, with a decline in testosterone levels, and all males responded to the ACTH injection with an increase in testosterone levels.

\section{Blood parameters and immune response}

We used three indices to assess condition and immunocompetence in the male classes: hematocrit, white blood cell number, and response to a foreign antigen challenge. First, adult nonbreeding males had significantly higher hematocrits at BASE (46.4 $\pm 0.9 \%)$ than either adult breeding $(39.9 \pm 1.3 \%)$ or juvenile males $(41.8 \pm 0.8 \%)$, which were similar $(F=10.5, \mathrm{df}=2$, $27, P=0.0004)$. Thus, nonbreeding males must have been in better condition.

Second, adult nonbreeding males had over twice as many white blood cells per field of view than did adult breeding males; juveniles were intermediate (Table 3). The proportions of the various white blood cell types, with the exception of eosinophils, were similar in all three male classes. Adult nonbreeding males had significantly fewer eosinophils than the other two male 
TABLE 3. Concentration and composition of the major types of white blood cells from blood smears of the three classes of male arctic ground squirrels $(N=10$ for each class $)$.

\begin{tabular}{|c|c|c|c|c|c|}
\hline \multirow[b]{2}{*}{ Male class } & \multicolumn{4}{|c|}{ White blood cell type (per 100) } & \multirow{2}{*}{$\begin{array}{l}\text { No. cells per } \\
\text { field view** }\end{array}$} \\
\hline & Neutrophils & Lymphocytes & Monocytes & Eosinophils* & \\
\hline Adult breeding & $64.0 \pm 1.0$ & $31.9 \pm 1.0$ & $2.2 \pm 0.4$ & $1.9^{\mathrm{a}} \pm 0.5$ & $0.9^{\mathrm{a}} \pm 0.2$ \\
\hline Adult nonbreeding & $63.5 \pm 1.0$ & $34.8 \pm 0.8$ & $1.4 \pm 0.6$ & $0.3^{b} \pm 0.2$ & $1.9^{\mathrm{b}} \pm 0.1$ \\
\hline Juvenile & $62.9 \pm 1.0$ & $34.6 \pm 1.0$ & $1.2 \pm 0.3$ & $1.3^{\mathrm{a}} \pm 0.3$ & $1.2^{\mathrm{a}} \pm 0.1$ \\
\hline
\end{tabular}

Note: Values are expressed as means $\pm 1 \mathrm{SE}$, and those with the same superscript letter are not significantly different. $* P<0.01$, ** $P<0.0001$.

classes (only $16 \%$ of that found in adult breeding males). This cell type is known to increase with parasitic infections (Bullock and Rosendahl 1984).

Third, differences in white cell concentrations among the male classes were dramatically reflected in the ability to mount an immune response to the foreign antigen, sheep red blood cells (Fig. 3). Antibody titer differed significantly among the male classes $(F=$ 96.7, df $=2,27, P<0.0001)$, with those in adult nonbreeding males being highest, in juvenile males intermediate, and in adult breeding males lowest. Thus, these three measures of condition and immunocompetence indicate that adult breeding males were in worse immunological condition than either of the other classes.

\section{DISCUSSION}

We have demonstrated that male arctic ground squirrels at different stages of their life cycle differ markedly in their ability to handle hormonal and immunological challenges. This ability is worst in adult breeding males, intermediate in juvenile nonbreeding males, and best in adult nonbreeding males. Many, but not all, of these changes in adult breeding males are very similar to those observed in dasyurid species in which males all die shortly after the mating season (Bradley et al. 1980, McDonald et al. 1981, 1986, Bradley 1987,

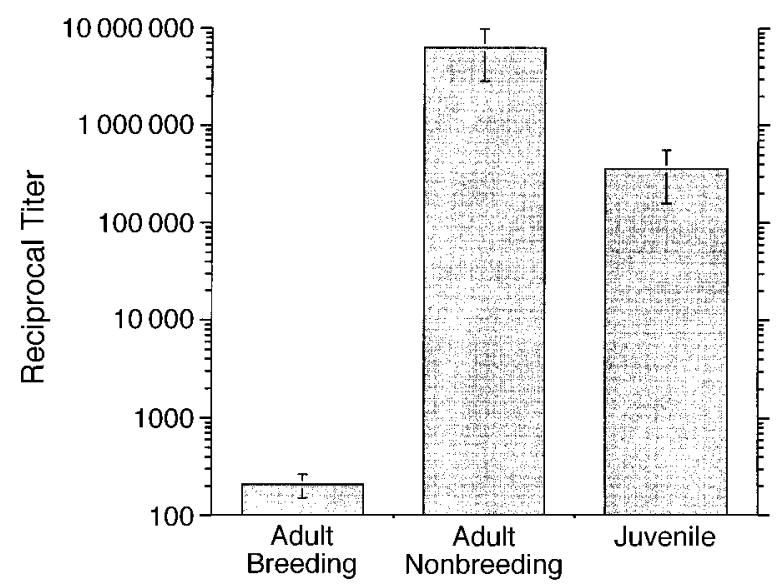

FIG. 3. Antibody titer response (note the log scale) to injected sheep red blood cells in serum of three classes $(N=$ 10 for each class) of male arctic ground squirrels (means $\pm 1 \mathrm{SE})$.
1990). In these dasyurid species, males during the breeding season have high levels of free cortisol, low levels of MCBC, pronounced dexamethasone resistance, and a poor immune response. In arctic ground squirrels, adult breeding males have the highest levels of free cortisol (Table 1, Fig. 2), the lowest MCBC levels (Table 1, Fig. 2), slight evidence of dexamethasone resistance, and a very poor immune response (Fig. 3). They have the lowest hematocrit and the lowest number of white blood cells (Table 3), as well as the highest number of eosinophils (Table 3 ). However, unlike the situation in the dasyurids, we estimate that $\sim 50 \%$ of the adult breeding males disappear in spring because they have died. Our evidence is consistent with the prediction that breeding male arctic ground squirrels experience the effects of chronic stress. We will discuss first the responses to the hormonal challenge and then the life history consequences for these responses.

\section{Hormonal challenge response}

In many species, chronic stress results in a greater capacity to produce and release glucocorticoids because of adrenal hypertrophy (Christian 1980, Harvey et al. 1984, Miller and Tyrrell 1995). However, this cannot be the explanation for the differences we see between adult breeding males and the other two male classes, because the total amount of cortisol in plasma was lower, not higher, in the adult breeding males. For example, at BASE, the level of the total (as opposed to free) cortisol in plasma was significantly lower $(F$ $=21.0$, df 2, 27, $P<0.0001)$ in adult breeding males $(125.6 \pm 7.2 \mathrm{ng} / \mathrm{mL})$ than in adult nonbreeding males $(215.5 \pm 13.5)$ or in juvenile males $(187.2 \pm 8.2)$. Thus, the higher levels of free cortisol in adult breeding males over the entire experiment was entirely the result of very low MCBC levels, as we will discuss. Adult breeding males also showed minor dexamethasone resistance relative to the other two classes (cortisol levels in breeding males fell $94 \%$ from that at BASE vs. $96 \%$ for adult nonbreeding males and $98 \%$ for juvenile males; Fig. 2). However, this is in marked contrast to DEX resistance in dasyurid males, in which virtually no decline in cortisol occurs when DEX is given (cortisol levels fell only $27 \%$ in A. swainsonii [McDonald et al. 1986] and only $10 \%$ in P. calura [Bradley 1990]). Thus, clearly the HPA axis is still responsive to cir- 
culating glucocorticoid levels in adult breeding males, as it is in the other male classes, and the negative feedback loop between the adrenal glands and the HPA is still functional. This modest dexamethasone resistance is also seen in snowshoe hares chronically stressed by high predation risk during the population decline of the 10-yr cycle (Boonstra et al. 1998).

The maximum corticosterone binding capacity (our measure of $\mathrm{CBG}$, the glucocorticoid binding globulin) was about three times higher in adult nonbreeding males than in breeding males (Fig. 2). The question is, what causes this decline in breeding males? The most plausible explanation for the dramatic decline in MCBC levels in adult breeding males is that chronic stress associated with intense male-male competition for access to females in the spring caused the lower MCBC levels. Chronic stress in mammals is known to cause a decline in CBG levels (Dallman et al. 1990, Armario et al. 1994, Fleshner et al. 1995). The other possibility is that increasing testosterone levels are responsible. In a number of species, there is an inverse relationship between testosterone levels and CBG levels. In male Antechinus spp. (Bradley et al. 1980, McDonald et al. 1981), increasing concentrations of testosterone cause MCBC levels to fall. In male Rattus fuscipes, there is also an inverse relationship between testosterone levels and CBG levels (McDonald et al. 1988). In contrast, no relationship was found between testosterone concentrations and CBG levels in Microtus pennsylvanicus (Boonstra and Boag 1992), in Microtus townsendii (McDonald and Taitt 1982), or in another dasyurid marsupial, Sminthopsis crassicaudata (McDonald et al. 1981). Arctic ground squirrel males fall into the latter group and show no relationship between testosterone levels and MCBC levels (Fig. 2): testosterone levels did not differ among the three classes of males, but MCBC levels differed markedly. Thus, we interpret the low levels of MCBC in adult breeding squirrels to indicate that they were chronically stressed.

The energy mobilization differences among the three classes of males were not as predicted (Fig. 2). We will address these changes at two levels: first with respect to the basic responses of the ground squirrels to the challenge protocol, and second with respect to the possible explanations of why the three classes responded as they did. Cortisol is known to promote gluconeogenesis, and the glucose should be stored in the liver as glycogen (Miller and Tyrrell 1995). In mammals, both DEX (an artificial glucocorticoid) and ACTH are known to mobilize glucose from liver glycogen reserves (Dallman et al. 1989). However, in ground squirrels we saw no evidence of major changes in glucose mobilization in response to the injections (Fig. 2). This stands in marked contrast to the responses of snowshoe hares (Boonstra et al. 1998), in which both DEX and ACTH resulted in marked increases in glucose levels. Thus, ground squirrel males throughout the active sea- son appear fundamentally different from other mammals with respect to glucose mobilization; thus, this measure may not be a good index of the degree of chronic stress to which they have been exposed. In contrast, their mobilization of FFA in response to the protocol is similar to that in other mammals. DEX causes a decrease, and ACTH an increase, in FFA levels (Fig. 2). ACTH is known to be a potent lipolytic hormone (Boston and Cone 1996, Boonstra and Tinnikov 1998), causing a rapid mobilization of FFA. Thus, when DEX is injected first, it presumably acts to inhibit ACTH release through negative feedback on the HPA axis, causing FFA levels to fall; when ACTH is subsequently injected, FFA is rapidly mobilized. These results suggest that stressors in the active season appear to mobilize energy largely through the mobilization of fats.

We had expected that adult breeding males would have the greatest capacity to mobilize glucose, and that this should come at the expense of peripheral sources of energy such as FFA. However, juvenile males had the highest glucose levels, both at BASE and over the experiment (higher than those in adult nonbreeding males, and similar to those in breeding males; Fig. 1, Table 2). This may be related to very low fat reserves in juveniles and to lower fat reserves in adult breeding males (Kiell and Millar 1980). Buck and Barnes (1996a: Fig. 2), from a detailed study on changes in body composition of squirrels from northern Alaska, found that juvenile males in mid-August had no fat reserves at all, and that breeding males at the end of the mating period (a period comparable to our sampling time) reached their lowest level of fat reserves $(7.5 \%$ of body mass, from a maximum spring level of $22 \%$ ). Thus when stressed, juveniles are forced to rely more heavily on glucose reserves.

As expected, adult breeding males had a significantly lower ability to mobilize FFA than did adult nonbreeding males (Table 1, Fig. 2), and this was similar to FFA mobilization in juveniles. By mid-August, Buck and Barnes (1999a) found that adult nonbreeding males had fat reserves of $\sim 13 \%$ of body mass and that this rapidly increased to reach $30 \%$ just prior to immergence. Thus, differences in ability to mobilize FFA may be a direct reflection of fat reserves, with juveniles and adult breeding males having the lowest levels and adult nonbreeding males the highest. The size of those reserves in adults is clearly a direct reflection of the preceding life history stressors, with breeding males having just come through the period of intense male-male mating competition, and with juveniles having had little opportunity to build up these reserves while dispersing from their natal site and competing with older animals for a hibernaculum.

\section{Immune response and condition}

High levels of chronic stress result in immunosuppression (Kelley 1985, Biondi and Zannino 1997). 
Adult breeding males had significantly lower numbers of lymphocytes and higher numbers of eosinophils than did adult nonbreeding males; juvenile males were similar to breeding males (Table 3). Stress is known to decrease lymphocyte function (Keller et al. 1984) and eosinophilia is known to be associated with parasitic worm infections (Bullock and Rosendahl 1984). Hence, this may be a reflection of higher levels of parasitism in adult breeding and juvenile males. Thus, adult breeding males were compromised immunologically, and this conclusion is dramatically reinforced by the virtual inability to mount an antibody response to the immunocompetence challenge with sheep red blood cells (Fig. 3). In contrast, the response in adult nonbreeding males was extremely high; that in juvenile males was also high, but intermediate (Fig. 3). Dasyurid males at the end of the mating period also exhibit a severely compromised immune system (Bradley et al. 1980) and, just prior to death, there is a heavy parasitism by a variety of diseases, including helminths (Barker et al. 1978).

Hematocrit, which can be an indicator of condition (Franzmann and LeResche 1978, Lochmiller et al. 1986, Hellgren et al. 1993, Boonstra et al. 1998), was also markedly different among males, with adult nonbreeding males having levels $6.5 \%$ higher than adult breeding males and $4.6 \%$ higher than juvenile males. These differences are probably related to two things. First, the spleen, a storage site for erythrocytes, contracts in response to an adrenalin surge caused by the stress and releases erythrocytes into the blood (Guthrie et al. 1967, Cross et al. 1988, Delgiudice et al. 1990), causing a temporary increase in hematocrit. Trapping and handling stresses the squirrels (Boonstra et al. 2001), and thus the hematocrit levels we obtained at the base bleed were those of animals already stressed. However, our results indicate that adult nonbreeding males have a significantly greater capacity to respond to this stressor than do adult breeding and juvenile males. We suggest that in adult breeding males, the stress of intense male-male competition during the breeding season depletes the spleen's ability to respond. Second, laboratory studies indicate that glucocorticoids directly inhibit erythrocyte production (Zalman et al. 1979, Leung and Gidari 1981). Thus, in adult breeding males, the high cortisol levels caused by the intense stress of male-male competition in the breeding season may directly depress red blood cell levels.

\section{Testosterone response}

The changes in testosterone $(\mathrm{T})$ levels in male arctic ground squirrels are remarkable for two reasons: first, we found no difference in $T$ levels among the three classes of males at either BASE or in response to the challenge test (Fig. 2), even though only the breeding males were scrotal; second, we found that ACTH (our simulated stressor, which caused a rapid increase in cortisol) actually increased, rather than decreased, T levels. With respect to the first point, the typical mammalian response for seasonally breeding males is for testosterone levels to decline to low levels when the males are not breeding (reviewed by Lincoln and Short 1980). A number of ground squirrel species show this typical pattern. Holekamp and Talamantes (1992) found that male California ground squirrels (Spermophilus beecheyi) (adults and yearlings were similar) had peak values of $\sim 5-6 \mathrm{ng} / \mathrm{mL}$ just before or during the mating period in January, and that values declined to $<1 \mathrm{ng} / \mathrm{mL}$ by May just before the males estivated for the summer. Barnes (1996) found that male goldenmantled ground squirrels (Spermophilus lateralis) had peak values of $\sim 3 \mathrm{ng} / \mathrm{mL}$ during the mating period in late April-early May, and that this declined to $\sim 0.1$ $\mathrm{ng} / \mathrm{mL}$ by July. In marked contrast, Barnes (1996) in Alaska and we (Table 1, Fig. 2) found T levels to be high in arctic ground squirrels both at the mating period and at the end of the summer. Barnes (values obtained from the graph with a digitization program) reported that baseline $\mathrm{T}$ levels in adult breeding males in early May were high $(3.37 \pm 0.27 \mathrm{ng} / \mathrm{mL}$, mean $\pm 1 \mathrm{sE}, N$ $=22$ ) and similar to those of adult nonbreeding males $(5.01 \pm 0.20 \mathrm{ng} / \mathrm{mL}, N=9)$ and of juvenile males $(5.35 \pm 0.50 \mathrm{ng} / \mathrm{mL}, N=9)$ in mid-August, even though paired testes sizes were 3-4 times larger in early May (mean $\pm 1 \mathrm{SE}=2.54 \pm 0.28 \mathrm{~g}, N=7$ ) than in late August $(0.74 \pm 0.10 \mathrm{~g}, N=4)$ in adult males and in juvenile males $(0.20 \mathrm{~g}, N=5$, no SE given) (data from Barnes 1996: Fig. 2). Thus, the high T levels that we found in both the breeding and nonbreeding periods were repeatable between studies and appear to be a feature of the yearly activity cycle of arctic ground squirrel males.

With respect to the second point, psychogenic or physical stressors that cause an increase in glucocorticoid levels are known to suppress $\mathrm{T}$ levels and male reproduction (Greenberg and Wingfield 1987, Levine et al. 1989, Sapolsky 1992). However, recent evidence from a number of field studies indicates that high levels of the stress hormones do not invariably compromise the ability to reproduce. Among social mammals such as dwarf mongooses (Helogale parvula; Creel et al. 1996) and African wild dogs (Lycaon pictus; Creel et al. 1997), and in birds (Wingfield et al. 1991) dominants or territorial individuals have high levels of corticosteroids, yet continue to reproduce. Our results of an increase in $\mathrm{T}$ levels following the ACTH injection (Fig. 2) echo these findings. In wildlife studies as well, the stress of capture and handling typically results in a decline in $\mathrm{T}$ levels, e.g., in snowshoe hares (Lepus americanus; Boonstra and Singleton 1993) and olive baboons (Papio anubis; Sapolsky 1985). However, the opposite occurred in arctic ground squirrels: from samples collected in early May, either instantaneously (by shooting) or after the squirrels were stressed by trapping and handling, $T$ levels were significantly lower in 
shot samples $(9.65 \pm 2.25 \mathrm{ng} / \mathrm{mL}, N=10)$ than in trapped and handled ones $(14.20 \pm 0.92 \mathrm{ng} / \mathrm{mL}, N=$ 48) $(F=6.6$, df 1, 56, $P=0.01)$ (Boonstra et al. 2001). Thus the positive response of T to ACTH and to trapping suggests that natural stressors (such as male-male aggression) augment $\mathrm{T}$ levels in arctic ground squirrels.

In ground squirrels, the critical unknown is the source of $\mathrm{T}$, given that two of our male classes were not scrotal. The literature suggests that it may, in fact, be originating from the adrenals through ACTH-induced stimulation of adrenal androgens. In mammals such as various primates (chimpanzees and humans), but not rodents, ACTH is known to stimulate the adrenal production and release of androgens such as dehydroepiandrosterone (Odell and Parker 1984-85). However, we have found no study that implicates ACTH as stimulating adrenals to produce T. Nevertheless our data strongly implicate an adrenal role in arctic ground squirrels. The DEX injection resulted in a reduction in T levels (Fig. 2) and, although this typically comes about as a result of the negative effects of glucocorticoids (such as DEX) on reproductive function operating at the level of the HPA axis and gonads (Vinson and Renfree 1975, Bambino and Hsuch 1981, Sapolsky 1985, McDonald et al. 1986, Bradley 1990), DEX will also inhibit pituitary release of ACTH as part of the negative feedback loop. In addition, although ACTH is a potent modulator of corticosterone release, it has much lower potency as a modulator of adrenal androgen release (Odell and Parker 1984-85). After the ACTH injection, we observed a much more dramatic increase of cortisol than of T. Hence, the decline in $\mathrm{T}$ that we observed after DEX may be a result of a decline in ACTH, which would then not be available to stimulate adrenal release of androgens. Thus, this may represent a unique phenomenon of male arctic ground squirrels, but the source of $\mathrm{T}$ must be investigated through further experiments.

However, the question ultimately must be: what is it about the biology of male arctic ground squirrels that requires high $\mathrm{T}$ levels, the release of which is increased by stressors? We suggest that, in this species, $\mathrm{T}$ is critical to maintaining aggressive and territorial behavior both in spring and in late summer. In spring, high levels of aggressive behavior are required to permit competition for access to females during the short, intense mating season (Carl 1971, Lacey et al. 1997), even though the males exhibit chronic stress symptoms as a result of these interactions (Fig. 2). In late summer, high levels of aggressive behavior may be required for two purposes. First, this behavior may be required to obtain and maintain territories and hibernacula near females, which will advantageously position these males for the ensuing competition in the next spring (Carl 1971, Green 1977, Barnes 1996). Second, this behavior may be required for males to defend their underground storage of food caches (females do not cache; Carl 1971, McLean and Towns 1981, Buck and
Barnes 1999a), which are required to permit a prolonged period of euthermy and gonadal maturation prior to emergence in spring. In contrast to what we are proposing, the presence of $\mathrm{T}$ is not necessary to maintain fall territoriality in a variety of bird species, e.g., Mockingbirds, Mimus polyglotlos (Logan and Wingfield 1990), European Robins, Erithacus rubecula (Schwable and Kriner 1991), Song Sparrows, Melospiza melodia (Wingfield 1994), as even castration will not suppress this territorial behavior. Therefore, unlike the situation found in laboratory rodents and in some primates in which there is a poor correlation between $\mathrm{T}$ levels and rates of aggression or dominance (Monaghan and Glickman 1992), our results imply that the presence of high levels of testosterone is a prerequisite for mediating aggressive behavior in early spring and late summer (Yahr 1983, Holekamp and Talamantes 1992).

\section{Profile of juvenile males}

The focus of this research has been on the physiological profile of adult breeding males. However, our evidence indicates that juvenile males also showed strong evidence of the effects of chronic stress. This may be directly related to the fact that the majority of young males disperse from the natal site in their summer of birth and must find and defend a hibernaculum before winter (Carl 1971, Green 1977, Buck and Barnes 1999a, Lacey 1991, Byrom and Krebs 1999). Juvenile male arctic ground squirrels are in competition for a hibernaculum with their surviving fathers, who have preceded them in dispersing to prime areas, which places the juveniles under very significant predation risk (Byrom and Krebs 1999). Juveniles in this study had a very rapid and dramatic response to ACTH, low numbers of white blood cells and high numbers of eosinophils (Table 3), low hematocrit levels, and levels of FFA that were all comparable to those in adult breeding males (Fig. 2). Their ability to mount an immune response to an antigen challenge was significantly lower than that of nonadult breeding males, although higher than that of adult breeding males (Fig. 3). In addition, they had the highest levels of glucose (Fig. 2). Buck and Barnes (1999a) report that juvenile arctic ground squirrels gain mass from their first appearance above ground in early summer until 1 August, but thereafter loose $16-18 \%$ of their body mass, during a period associated with dispersal from the natal burrow. Thus, all of this evidence is consistent with the interpretation that juvenile males in mid-August had or were experiencing chronic stress associated with dispersal.

\section{Life history consequences}

In virtually all ground squirrel species, there is a significant skewing of sex ratios in favor of females in breeding animals (Fig. 1; Boag and Murie 1981: Table 10). The mating period and the immediate postmating period are the critical ones when some of this skewing 
takes place. We found that almost half of the males present in the spring mating period disappeared shortly thereafter, and of those that disappeared, most must have died, because they were not replaced by an equal number of immigrants. Michener and McLean (1996) found that in Richardson's ground squirrel ( $S$. richardsonii), $55 \%$ of the breeding males disappeared immediately after the breeding season and were not seen again. Sherman and Morton (1984) concluded that in Belding's ground squirrel ( $S$. beldingi), many, if not most, of the disappearances during and following the mating competition were due to death and not dispersal. From the work on the dasyurids in which the impact of male-male interactions has been decoupled from the impact of mating behavior, it is aggressive behavior that increases ACTH and cortisol levels, and ultimately causes death (Lee and McDonald 1985, Scott 1987). Our physiological results in male arctic ground squirrels are consistent with the explanation that, in ground squirrel species generally, the stress of intense intrasexual competition during the breeding season compromises their condition and immune system which, for many of them, directly causes death. Thus, male ground squirrels trade off survival for reproduction and we view this as a life history adaptation to maximize fitness.

This research leaves four areas unresolved that should be investigated. First, we were not able to decouple the potential differences between breeding yearlings and breeding older males. Do old adult males show more extreme stress responses than yearlings because their residual reproductive effort is lower. If so, is this extreme stress compensated for by adult males fathering more young than yearlings? Second, if older males do show more extreme stress responses, do yearlings survive better than adults after the breeding season? Third, as testosterone is high in all classes of males, independent of age or reproductive status, what is its role in behavior and what is its source? Finally, are similar adaptive stress responses occurring in mammal (e.g., red deer; Clutton-Brock et al. 1988) and bird species (e.g., Sage Grouse; Vehrencamp et al. 1989) that have comparable mating patterns: short mating periods with intense male-male interactions that may compromise subsequent survival?

\section{ACKNOWLEDGMENTS}

We thank the Natural Sciences and Engineering Research Council of Canada for providing funds to R. Boonstra, and the University of Toronto for scholarship support to C. J. McColl and T. J. Karels. We thank two reviewers for improving the manuscript, thank the Arctic Institute of North America, University of Calgary, for use of the facilities at the Kluane Lake Base, and S.-L. Kuo and C. Coltas for laboratory analysis. This is contribution Number 134 of the Kluane Boreal Forest Ecosystem Project.

\section{Literature Cited}

Abraham, G. E., R. S. Swerdloff, D. Tulchinsky, and W. D. Odell. 1971. Radioimmunoassay of plasma progesterone. Journal of Clinical Endocrinology 32:619-624.
Armario, A., M. Giralt, O. Marti, A. Gavalda, J. Hidalgo, B. R. S. Hsu, and R. W. Kuhn. 1994. The effect of acute and chronic ACTH administration on pituitary-adrenal response to acute immobilization stress: relationship to changes in corticosteroid-binding globulin. Endocrine Research 20:139-149.

Astheimer, L. B., W. A. Buttener, and J. C. Wingfield. 1994. Gender and seasonal differences in the adrenocortical response to ACTH challenge in an arctic passerine, Zonotrichia leucophrys gambelii. General and Comparative Endocrinology 94:33-43.

Bambino, T., and A. Hsuch. 1981. Direct inhibitory effect of glucocorticoids upon testicular luteinizing hormone receptor and steroidgenesis in vivo and in vitro. Endocrinology 108:2142-2153.

Banfield, A. W. F. 1974. The mammals of Canada. National Museum of Canada and University of Toronto Press, Toronto, Ontario, Canada.

Barker, I. K., I. Beveridge, A. J. Bradley, and A. K. Lee. 1978. Observations on spontaneous stress-related mortality among males of the dasyurid marsupial Antechinus stuartii Macleay. Australian Journal of Zoology 26:435-447.

Barnes, B. M. 1996. Relationship between hibernation and reproduction in male ground squirrels. Pages 71-80 in F. Geiser, A. J. Hulbert, and S. C. Nicol, editors. Adaptations to the cold. Tenth International Hibernation Symposium. University of New England Press, Armidale, Australia.

Biondi, M., and L. G. Zannino. 1997. Psychological stress, neuroimmunomodulation, and susceptibility to infectiousdiseases in animals and man: a review. Psychotherapy and Psychosomatics 66:3-26.

Boag, D. A., and J. O. Murie. 1981. Population ecology of Columbian ground squirrels in southwestern Alberta. Canadian Journal of Zoology 59:2230-2240.

Boonstra, R., and P. T. Boag. 1992. Spring declines in Microtus pennsylvanicus and the role of steroid hormones. Journal of Animal Ecology 61:339-352.

Boonstra, R., D. Hik, G. R. Singleton, and A. Tinnikov. 1998. The impact of predator-induced stress on the snowshoe hare cycle. Ecological Monographs 68:371-394.

Boonstra, R., A. H. Hubbs, E. A. Lacey, and C. J. McColl. 2001. Seasonal changes in glucocorticoid and testosterone concentrations in free-living arctic ground squirrels from the boreal forest of the Yukon. Canadian Journal of Zoology 79:49-58.

Boonstra, R., and G. R. Singleton. 1993. Population declines in the snowshoe hare and the role of stress. General and Comparative Endocrinology 91:126-143.

Boonstra, R., and A. A. Tinnikov. 1998. Increased corticosteroid binding capacity of plasma albumin but not of CBG caused by ACTH induced changes in free fatty acid concentrations in snowshoe hares and rabbits. Journal of Endocrinology 156:205-212.

Boston, B. A., and R. D. Cone. 1996. Characterization of melanocortin receptor subtype expression in murine adipose tissues and in the 3T3-L1 cell line. Endocrinology 137:2043-2050.

Boutin, S., et al. 1995. Population changes of the vertebrate community during a snowshoe hare cycle in Canada's boreal forest. Oikos 74:69-80.

Bradley, A. J. 1987. Stress and mortality in the red-tailed phascogale Phascogale calura (Marsupialia: Dasyuridae). General and Comparative Endocrinology 67:85-100.

Bradley, A. J. 1990. Failure of glucocorticoid feedback during breeding in the male red-tailed phascogale Phascogale calura (Marsupialia: Dasyuridae). Journal of Steroid Biochemistry and Molecular Biology 37:155-163.

Bradley, A. J., I. R. McDonald, and A. K. Lee. 1980. Stress and mortality in a small mammal (Antechinus stuartii 
MacLeay). General and Comparative Endocrinology 40: $188-200$

Buck, C. L., and B. M. Barnes. 1999a. Annual cycle of body composition and hibernation in free-living arctic ground squirrels. Journal of Mammalogy 80:430-442.

Buck, C. L., and B. M. Barnes. 1999b. Temperatures of hibernacula and changes in body composition of arctic ground squirrels over winter. Journal of Mammalogy 80: 1264-1276.

Bullock, B. L., and P. P. Rosendahl. 1984. Pathophysiology. Little, Brown and Company, Boston, Massachusetts, USA.

Byrom, A. E., T. Karels, C. J. Krebs, and R. Boonstra. 2000. Experimental manipulation of predation and food for arctic ground squirrels in the boreal forest. Canadian Journal of Zoology 78:1309-1319.

Byrom, A. E., and C. J. Krebs. 1999. Natal dispersal of juvenile arctic ground squirrels in the boreal forest. Canadian Journal of Zoology 77:1048-1059.

Carl, E. A. 1971. Population control in arctic ground squirrels. Ecology 52:395-413.

Christian, J. J. 1980. Endocrine factors in population regulation. Pages 55-115 in M. N. Cohen, R. S. Malpass, and H. G. Klein, editors. Biosocial mechanisms of population regulation. Yale University Press, New Haven, Connecticut, USA.

Clutton-Brock, T. H., S. D. Albon, and F. E. Guinness. 1988. Reproductive success in male and female red deer. Pages 325-343 in T. H. Clutton-Brock, editor. Reproductive success. University of Chicago Press, Chicago, Illinois, USA.

Creel, S., N. M. Creel, M. G. L. Mills, and S. L. Monfort. 1997. Rank and reproduction in cooperatively breeding African wild dogs: behavioral and endocrine correlates. Behavioral Ecology 8:298-306.

Creel, S., N. M. Creel, and S. L. Monfort. 1996. Social stress and dominance. Nature 379:212.

Cross, J. P., C. G. MacKintosh, and J. F. T. Griffin. 1988. Effect of physical restraint and xylazine sedation on haematological values in red deer (Cervus elaphus). Research in Veterinary Science 45:281-286.

Croze, F., and R. J. Etches. 1980. The physiological significance of androgen-induced ovulation in the hen. Journal of Endocrinology 84:163-171.

Dallman, M. F., S. F. Akana, C. S. Cascio, D. N. Darlington, L. Jacobson, and N. Levin. 1990. Regulation of ACTH secretion: variations on a theme of B. Recent Progress in Hormone Research 43:113-173.

Dallman, M. F., N. Levin, C. S. Cascio, S. F. Akana, L. Jacobson, and R. W. Kuhn. 1989. Pharmacological evidence that the inhibition of diurnal adrenocorticotropin secretion by corticosteroids is mediated by type I corticosteronepreferring receptors. Endocrinology 124:2844-2850.

Day, R. W., and G. P. Quinn. 1989. Comparisons of treatment after an analysis of variance in ecology. Ecological Monographs 59:433-463.

Debro, J. R., H. Traver, and A. Korner. 1957. The determination of serum albumin and globulin by a new method. Journal of Laboratory and Clinical Medicine 50:728-732.

Delgiudice, G. D., K. E. Kunkel, L. D. Mech, and U. S. Seal. 1990. Minimizing capture-related stress on white-tailed deer with a capture collar. Journal of Wildlife Management 54:299-303.

Doe, R. P., R. Fernandez, and U. S. Seal. 1964. Measurement of corticosteroid binding globulin in man. Journal of Clinical Endocrinology and Metabolism 24:1029-1039.

Englund, P. T., J. A. Huberman, T. M. Jovin, and A. Kornberg. 1969. Enzymatic synthesis of deoxyribonucleic acid. XXX. Binding of triphosphates to deoxyribonucleic polymerase. Journal of Biological Chemistry 244:3038-3044.

Fleshner, M., T. Deak, R. L. Spencer, M. L. Laudenslager, L. R. Watkins, and S. F. Maier. 1995. A long term increase in basal levels of corticosterone and a decrease in corticosteroid-binding globulin after acute stressor exposure. Endocrinology 136:5336-5342.

Franzmann, A. W., and R. E. LeResche. 1978. Alaskan moose blood studies with emphasis on condition evaluation. Journal of Wildlife Management 42:334-351.

Gagnon, J., J. Roth, B. Finzer, R. Hofmann, K. Haycock, J. Simpson, and D. Feldman. 1990. SuperANOVA-Accessible General Linear Modelling. Abacus Concepts, Berkeley, California, USA.

Galster, W., and P. R. Morrison. 1975. Gluconeogenesis in arctic ground squirrels between periods of hibernation. American Journal of Physiology 228:325-330.

Green, J. E. 1977. Population regulation and annual cycles of activity and dispersal in the Arctic ground squirrel. Thesis. University of British Columbia, Vancouver, British Columbia, Canada.

Greenberg, N., and J. C. Wingfield. 1987. Stress and reproduction: reciprocal relationships. Pages 461-503 in D. O. Norris and R. E. Jones, editors. Hormones and reproduction in fishes, amphibians, and reptiles. Plenum Press, New York, New York, USA.

Guthrie, D. R., J. C. Osborne, and H. S. Mosby. 1967. Physiological changes associated with shock in confined gray squirrels. Journal of Wildlife Management 31:102-108.

Harvey, S., J. G. Phillips, A. Rees, and T. R. Hall. 1984. Stress and adrenal function. Journal of Experimental Zoology 232:633-644.

Hellgren, E. C., L. L. Rogers, and U. S. Seal. 1993. Serum chemistry and hematology of black bears: physiological indices of habitat quality or seasonal patterns. Journal of Mammalogy 74:304-315.

Holekamp, K. E., and P. W. Sherman. 1989. Why male ground squirrels disperse. American Scientist 77:232-239.

Holekamp, K. E., and F. Talamantes. 1992. Seasonal fluctuations in hormones and behavior of free-living male California ground squirrels (Spermophilus beldingi). Hormones and Behavior 26:7-23.

Hoogland, J. L. 1982. Prairie dogs avoid extreme inbreeding. Science 215:1639-1641.

Hubbs, A. H., and R. Boonstra. 1997. Population limitation in Arctic ground squirrels: effects of food and predation. Journal of Animal Ecology 66:527-541.

Kalin, N. H., R. M. Cohen, G. W. Kraemer, S. C. Risch, S. Shelton, M. Cohen, W. T. McKinney, and D. L. Murphy. 1981. The dexamethasone suppression test as a measure of hypothalamic-pituitary feedback sensitivity and its relationship to behavioral arousal. Neuroendocrinology 32: 92-95.

Karels, T. J., A. E. Byrom, R. Boonstra, and C. J. Krebs. 2000. The interactive effects of food and predators on production and overwinter survival of Arctic ground squirrels. Journal of Animal Ecology 69:235-247.

Keller, S. E., S. J. Schleifer, and M. Stein. 1984. Stressinduced suppression of lymphocyte function in rats. Pages 10-121 in E. L. Cooper, editor. Stress, immunity, and aging. Marcel Dekker, New York, New York, USA.

Kelley, K. W. 1985. Immunological consequences of changing environmental stimuli. Pages 193-223 in G. P. Moberg, editor. Animal stress. American Physiological Society, Baltimore, Maryland, USA.

Keppel, G. 1982. Design and analysis. A researcher's handbook. Second edition. Prentice-Hall, Englewood Cliffs, New Jersey, USA.

Kiell, D. J., and J. S. Millar. 1980. Reproduction and nutrient reserves of arctic ground squirrels. Canadian Journal of Zoology 58:416-421.

Krebs, C. J., and R. Boonstra. 1978. Demography of the spring decline in populations of the vole, Microtus townsendii. Journal of Animal Ecology 47:1007-1015. 
Krebs, C. J., S. Boutin, R. Boonstra, A. R. E. Sinclair, J. N. M. Smith, M. R. T. Dale, K. Martin, and R. Turkington. 1995. Impact of food and predation on the snowshoe hare cycle. Science 269:1112-1115.

Lacey, E. A. 1991. Reproductive and dispersal strategies of male Arctic ground squirrels (Spermophilus parryii pleisus). Dissertation. University of Michigan, Ann Arbor, Michigan, USA.

Lacey, E. A., J. R. Wieczorek, and P. K. Tucker. 1997. Male mating behaviour and patterns of sperm precedence in Arctic ground squirrels. Animal Behaviour 53:767-779.

Laurell, S., and G. Tibbling. 1967. Colorimetric micro-determination of free fatty acids in plasma. Clinica Chimica Acta 16:57-62.

Lee, A. K., and A. Cockburn. 1985. Evolutionary ecology of marsupials. Cambridge University Press, Cambridge, UK.

Lee, A. K., and I. R. McDonald. 1985. Stress and population regulation in small mammals. Oxford Reviews of Reproductive Biology 7:261-304.

Leung, P., and A. S. Gidari. 1981. Glucocorticoids inhibit erythroid colony formation by murine fetal liver erythroid progenitor cells in vitro. Endocrinology 108:1787-1793.

Levine, S., C. Coe, and S. G. Wiener. 1989. Psychoneuroendocrinology of stress: a psychobiological perspective. Pages 341-377 in F. R. Brush and S. Levine, editors. Psychoendocrinology. Academic Press, San Diego, California, USA.

Lincoln, G. A., and R. V. Short. 1980. Seasonal breeding: nature's contraceptive. Recent Progress in Hormone Research 36:1-52.

Lochmiller, R. L., E. C. Hellgren, L. W. Varner, and W. E. Grant. 1986. Serum and urine biochemical indicators of nutritional status in adult female collared peccaries, Tayassu tajacu (Tayassuidae). Comparative Biochemistry and Physiology 83A:477-488.

Logan, C. A. and J. C. Wingfield. 1990. Autumnal territorial aggression is independent of plasma testosterone in mockingbirds. Hormones and Behavior 24:568-581.

McColl, C. J. 1998. The role of food, predation, and population density on the stress physiology of Arctic ground squirrels. Thesis. University of Toronto, Toronto, Ontario, Canada.

McColl, C. J., and R. Boonstra. 1999. Physiological effects of three inhalant anesthetics on Arctic ground squirrels. Wildlife Society Bulletin 27:946-951.

McDonald, I. R., A. K. Lee, A. J. Bradley, and K. A. Than. 1981. Endocrine changes in dasyurid marsupials with differing mortality patterns. General and Comparative Endocrinology 44:292-301.

McDonald, I. R., A. K. Lee, K. A. Than, and R. W. Martin. 1986. Failure of glucocorticoid feedback in males of a population of small marsupials (Antechinus swainsonii) during a period of mating. Journal of Endocrinology 108: 63-68.

McDonald, I. R., A. K. Lee, K. A. Than, and R. W. Martin. 1988. Concentration of free glucocorticoids in plasma and mortality in the Australian bush rat (Rattus fuscipes Waterhouse). Journal of Mammalogy 69:740-748.

McDonald, I. R., and M. J. Taitt. 1982. Steroid hormones in the blood plasma of Townsend's vole (Microtus townsendii). Canadian Journal of Zoology 60:2264-2269.

McLean, I. G. 1981. Social ecology of the Arctic ground squirrel Spermophilus parryii. Dissertation. University of Alberta, Edmonton, Alberta, Canada.

McLean, I. G. 1983. Paternal behaviour and killing of young in arctic ground squirrels. Animal Behavior 31:32-44

McLean, I. G., and A. J. Towns. 1981. Difference in weight changes and the annual cycle of male and female Arctic ground squirrels. Arctic 34:249-254.
Michael, S. E. 1962. The isolation of albumin from blood serum or plasma by means of organic solvents. Biochemical Journal 82:212-218.

Michener, G. R., and L. Locklear. 1990. Differential costs of reproductive effort for male and female Richardson's ground squirrels. Ecology 71:855-868.

Michener, G. R., and I. G. McLean. 1996. Reproductive behaviour and operational sex ratio in Richardson's ground squirrels. Animal Behaviour 52:743-758.

Miller, W. L., and J. B. Tyrrell. 1995. The adrenal cortex. Pages 555-711 in P. Felig, J. D. Baxter, and L. A. Frohman, editors. Endocrinology and Metabolism. Third edition. McGraw-Hill, New York, New York, USA.

Monaghan, E. P., and S. E. Glickman. 1992. Hormones and aggressive behavior. Pages 261-285 in J. B. Becker, S. M. Breedlove, and D. Crews, editors. Behavioral endocrinology. MIT Press, Cambridge, Massachusetts, USA.

Morton, M. L., and P. W. Sherman. 1978. Effects of a spring snowstorm on behavior, reproduction, and survival of Belding's ground squirrels. Canadian Journal of Zoology 56: 2578-2590

Munck, A., P. Guyre, and N. Holbrook. 1984. Physiological functions of glucocorticoids during stress and their relation to pharmacological actions. Endocrine Reviews 5:25-44.

Musacchia, X. J., and R. D. Hamilton. 1959. Notes on hibernation and awakening in Arctic ground squirrels. Journal of Mammalogy 40:201-204.

Odell, W. D., and L. N. Parker. 1984-1985. Control of adrenal androgen production. Endocrine Research 10:617630.

Paterson, J. Y. F., and F. Hills. 1967. The binding of cortisol by ovine plasma proteins. Journal of Endocrinology 37: 261-268.

Peters, T., Jr. 1996. All about albumin. Academic Press, San Diego, California, USA.

Romero, L. M., K. K. Soma, and J. C. Wingfield. 1998. The hypothalamus and adrenal regulate modulation of corticosterone release in redpolls (Carduelis flammea - an arctic-breeding song bird). General and Comparative Endocrinology 109:347-355.

Rosner, W. 1990. The functions of corticosteroid-binding globulin and sex hormone-binding globulin: recent advances. Endocrine Reviews 11:80-91.

Sandberg, A. A., and W. R. Slaunwhite, Jr. 1959. Transcortin: a corticosteroid-binding protein of plasma. II. Levels in various conditions and the effects of estrogens. Journal of Chemical Investigations 38:1290-1297.

Sapolsky, R. 1983. Individual differences in cortisol secretory patterns in the wild baboon: role of negative feedback sensitivity. Endocrinology 113:2263-2267.

Sapolsky, R. 1985. Stress induced suppression of testicular function in the wild baboon: role of glucocorticoids. Endocrinology 116:2273-2278.

Sapolsky, R. 1992. Neuroendocrinology of the stress-response. Pages 287-324 in J. B. Becker, S. M. Breedlove, and D. Crews, editors. Behavioral endocrinology. MIT Press, Cambridge, Massachusetts, USA.

Schwabl, H., and E. Kriner. 1991. Territorial aggression and song of male European robins (Erithacus rubecula) in autumn and spring: effects of antiandrogen treatment. Hormones and Behavior 28:1-15.

Scott, M. P. 1987. The effect of mating and agonistic experience on adrenal function and mortality of male Antechinus stuartii (Marsupialia). Journal of Mammalogy 68: 479-486.

Selye, H. 1946. The general-adaptation-syndrome and diseases of adaptation. Journal of Clinical Endrocrinology and Metabolism 6:117-230.

Sherman, P. W., and M. L. Morton. 1984. Demography of Belding's ground squirrels. Ecology 65:1617-1628. 
Siiteri, P. K., J. T. Murai, G. L. Hammond, J. A. Nisker, W. J. Raymoure, and R. W. Kuhn. 1982. The serum transport of steroid hormones. Recent Progress in Hormone Research 38:457-510.

Silverin, B., B. Arvidsson, and J. Wingfield. 1997. The adrenocortical responses to stress in breeding Willow Warblers Phylloscopus trochilus in Sweden: effects of latitude and gender. Journal of Animal Ecology 11:376-384.

Smith, J. H., and G. A. Bubenik. 1990. Plasma concentrations of glucocorticoids in white-tailed deer: the effect of acute ACTH and dexamethasone administration. Canadian Journal of Zoology 68:2123-2129.

Sokal, R. R., and F. J. Rohlf. 1995. Biometry: the principles and practice of statistics in biological research. W. H. Freeman, New York, New York, USA.

Vander, A. J., J. H. Sherman, and D. S. Luciano. 1990. Human physiology: the mechanisms of body function. McGrawHill, New York, New York, USA.

Vehrencamp, S. L., J. W. Bradbury, and R. M. Gibson. 1989. The energetic cost of display in male sage grouse. Animal Behaviour 36:885-896.

Vinson, G. P., and M. B. Renfree. 1975. Biosynthesis and secretion of testosterone by adrenal tissue from North American opossum Didelphis virginiana and the effects of trophic hormone stimulation. General and Comparative Endocrinology 27:214-222.
Winer, B. J. 1971. Statistical principles in experimental design. Second edition. McGraw-Hill, New York, New York, USA.

Wingfield, J. C. 1994. Control of territorial aggression in a changing environment. Psychoneuroendocrinology 19: 709-721.

Wingfield, J. C., R. E. Hegner, and D. M. Lewis. 1991. Circulating levels of luteinizing hormone and steroid hormones in relation to social status in the cooperatively breeding white-browed sparrow weaver, Plocepasser mahali. Journal of Zoology, London 225:43-58.

Wingfield, J. C., C. M. Vleck, and M. C. Moore. 1992. Seasonal changes of the adrenocortical response to stress in birds of the Sonoran Desert. Journal of Experimental Zoology 264:419-428.

Yahr, P. 1983. Hormonal influences on territorial marking behavior. Pages 145-175 in B. B. Svare, editor. Hormones and aggressive behavior. Plenum, New York, New York, USA.

Zalman, F., M. A. Maloney, and H. M. Patm. 1979. Differential responses of early erythropoietic and granulopoietic progenitors to dexamethasone and cortisone. Journal of Experimental Medicine 149:67-72.

Zar, J. H. 1984. Biostatistical analysis. Prentice-Hall, Englewood Cliffs, New Jersey, USA. 